\title{
Obituary
}

\section{Christopher (Chris) Freeman FRCPsych FRCP (Ed)}

\author{
Formerly Consultant Psychotherapist and Consultant \\ Psychiatrist, Royal Edinburgh Hospital, and Honorary \\ Professor, Queen Margaret University, Edinburgh
}

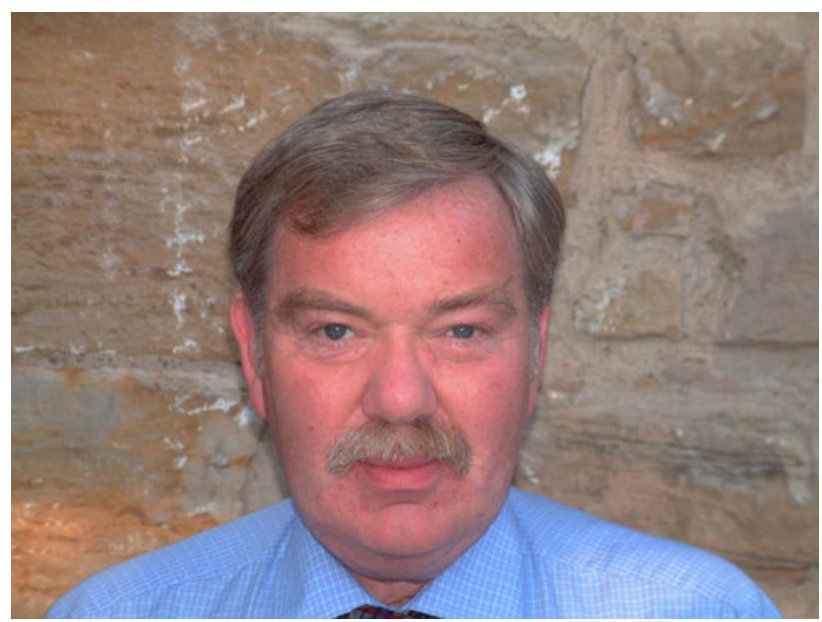

Christopher (Chris) Paul Lindsay Freeman, who recently died at the age of 70, had an unusually bright and enquiring mind and loved challenging existing orthodoxies. In 1978, while still a junior academic, he carried out a double-blind trial of the effectiveness of electroconvulsive therapy (ECT) - then, as now, a controversial intervention. The trial, which found 'real' ECT to be superior to 'sham' ECT, was published in The Lancet, a remarkable achievement for such a young researcher. Subsequently, he published a number of other key research papers, almost 150 publications in total. He also contributed substantially to the teaching of a generation of psychiatrists, personally writing chapters on neuroses, personality disorder and ECT for the Companion to Psychiatric Studies. In addition, he was co-editor of the 7th and 8th editions of this textbook, required reading for those studying for the MRCPsych qualification.

Despite his academic productivity, Chris was more interested in developing and improving services than in pursuing an academic career. His considerable energies went especially into his areas of expertise: psychotherapy as it relates to eating disorders, post-traumatic stress disorder and ECT. It is an indication of his breadth of knowledge that he chose to focus on opposite ends of the psychiatric treatment spectrum. Although his influence on psychological therapies in the treatment of eating disorders and trauma-related morbidity was broad, the most tangible evidence of his efforts was the establishment of the Cullen Centre at the Royal Edinburgh Hospital, the Anorexia Nervosa Intensive Treatment Team and the Regional Unit at St John's Hospital that provide, respectively, out-patient, community-based and in-patient treatment for people with eating disorders.

When he recognised the increasing number of referrals his service was receiving for the assessment and treatment of traumatic stress disorders, Chris took practical steps to meet the changing needs. He ensured that specialist services for people suffering from these disorders were available by establishing the Rivers Centre, together with Claire Fyvie. This centre was named after W. H. R. Rivers, the psychiatrist who worked at Craiglockhart Hospital during the First World War, and among whose patients were the poets Siegfried Sassoon and Wilfred Owen. Chris also undertook much related medico-legal work that ensured the condition was better understood by the courts and, where appropriate, that sufferers were compensated. He broadened his influence in this field by establishing the Scottish Trauma Advisory Group with direct links to the Scottish Government. He also served as President of the UK Psychological Trauma Society.

Chris had a strong interest in maintaining high standards in the quality of psychiatric care. In Scotland, he established the ECT Accreditation Service and later chaired a similar body for the Royal College of Psychiatrists. He also chaired the Ethics Committee of the College and most recently was its Clinical Lead for Quality Improvement.

After a childhood in York, Chris studied medicine at Edinburgh University Medical School, from where he graduated in 1971. He trained in psychiatry at the Royal Edinburgh Hospital, obtaining the Membership of the Royal College of Psychiatrists in 1976. Three years later, he was awarded the Gaskell Gold Medal. He was appointed Senior Lecturer at Edinburgh University Medical School and Honorary Consultant Psychiatrist at the Royal Edinburgh Hospital in 1980, but in 1984 surprised many with a move to a National Health Service Consultant post in Psychotherapy. Exploring new territory in psychotherapy, he changed the focus of the department from traditional psychoanalytically based psychotherapy to cognitive-behavioural therapy (CBT). He was able, with colleagues, to develop a training course in CBT for doctors, psychologists, nurses and other professionals. This grew to become the South of Scotland CBT course. The emphasis in therapy was on a positive collaboration with the patient, with the aim of developing the patient's motivation to change.

Chris's personality was characterised by his infectious enthusiasm, coupled with an eager willingness to take on new challenges. On occasion, his reluctance to turn down opportunities resulted in serious overload and a need to 'wing it'. When his 'just in time' approach became 'just too late', colleagues could be left spinning or catching falling plates. This sometimes led them to feel frustrated with him, but there was never any lasting animosity.

Although he placed great importance on getting personally involved with patients, carers and colleagues, he was never happier than when working with his hands in his garden or workshop. He was fascinated by new technology and its accompanying gadgets, but also spent a great deal of time and effort gathering an extensive collection of old children's toys. 
At an extremely well-attended memorial service for Chris held at the University of Edinburgh, Playfair Library, on 13 October 2017, colleagues from many different disciplines paid tribute to his massive contributions to the field. Chris was devoted to his family. At the service, his wife and two sons described his role as a family man whose happiest times in his later years were spent playing with his grandchildren.

A quotation from John Buchan on the cover of the order of service eloquently summed up his life.

'His presence warmed and lit up so big a region of life that in thinking of him one is overwhelmed by the multitude of things that he made better by simply existing among them.'

Born on 21 April 1947, Chris Freeman died of cancer of the prostate at home in East Lothian on 20 August 2017. He is survived by his wife Katherine, his sons Paul and Robin, and his grandchildren.

James Hendry, Tom Brown, and Derek Chiswick

doi:10.1192/bjb.2018.18

(c) The Authors 2018. This is an Open Access article, distributed under the terms of the CreativeCommons Attribution-NonCommercial-NoDerivatives licence (http://creativecommons.org/licenses/by-ncnd/4.0/), which permits non-commercial re-use, distribution, and reproduction in any medium, provided the original work is unaltered and is properly cited. The written permission of Cambridge University Press must be obtained for commercial re-use or in order to create a derivative work. 